\title{
Primary healthcare delivery models for uninsured low- income earners during the transition to National Health Insurance: Perspectives of private South African providers
}

\author{
S Girdwood, ${ }^{1,2}$ BCom Hons, MSc; K Govender, ${ }^{1,2}$ BSc Hons, MBA; L Long, ${ }^{1,2,3}$ MCom, PhD; J Miot, ${ }^{1,2}$ BPharm, PhD; G Meyer-Rath, ${ }^{1,2,3}$ MD, PhD \\ ${ }^{1}$ Department of Internal Medicine, Faculty of Health Sciences, University of the Witwatersrand, Johannesburg, South Africa \\ ${ }^{2}$ Health Economics and Epidemiology Research Office (HE $\left.{ }^{2} \mathrm{RO}\right)$, Wits Health Consortium, University of the Witwatersrand, Johannesburg, South Africa \\ ${ }^{3}$ Department of Global Health, Boston University School of Public Health, Boston, Mass., USA
}

Corresponding author: S Girdwood (sgirdwood@heroza.org)

\begin{abstract}
Background. The proposed National Health Insurance (NHI) system aims to re-engineer primary healthcare (PHC) provision in South Africa, with strategic purchasing of services from both private and public sector providers by the NHI Fund. Currently, while access to the private sector is primarily restricted to high-income insured earners, an important proportion of the low-income segment is choosing to utilise private PHC providers over public sector clinics. In recent years, a number of private providers in SA have established innovative models of PHC delivery that aim to expand access beyond the insured population and provide affordable access to good-quality PHC services.

Objectives. To describe the current landscape of private PHC clinic models targeting low-income, uninsured earners and the role they might play during the transition to NHI.

Methods. Key informant interviews were conducted with representatives of a sample of private PHC provider organisations providing services to low-income, uninsured earners with clinics - beyond the traditional private sector general practitioner model. Organisations were asked to describe their service delivery model, the population it serves, the PHC services offered and the financing model. Written responses were captured in Excel and coded manually, and the results were thematically analysed.

Results. Of the eight organisations identified, most have actively engaged strategies to ensure the provision of affordable quality care. Within these strategies, scale is an important pivot in spreading fixed costs across more paying patients as well as task shifting to lower cadres of healthcare workers. Access to government medicines and laboratory tests is an important factor in achieving lower costs per patient. Together, these strategies support the sustainability of these models.

Conclusions. We have provided an exploratory analysis of private PHC service delivery models serving the low-income, uninsured patient population, establishing factors that increase the efficiency of such service delivery, and delineating combinations of strategies that could make these models successful both during the transition to NHI and during full-scale NHI implementation. A clear regulatory framework would act as a catalyst for further innovation and facilitate contracting. These existing models can enhance and complement government provision and could be scaled up to meet the needs of expanding PHC under NHI. Understanding these models and the space and parameters in which they operate is important.
\end{abstract}

S Afr Med J 2019;109(10):771-783. https://doi.org/10.7196/SAMJ.2019.v109i10.13930

A robust, well-functioning primary healthcare (PHC) system is the mainstay of any healthcare system, and South Africa (SA)'s requirements are no different. It is estimated that properly delivered PHC services could greatly reduce the burden of premature mortality and disability by 21 $38 \%$ in children aged $<15$ years and by $10-18 \%$ in adults. ${ }^{[1]}$ Furthermore, improving health system quality and health service utilisation could avert $55 \%$ of excess mortality in low-income and middle-income countries relative to settings with strong health systems. ${ }^{[2]}$

The proposed National Health Insurance (NHI) system aims to re-engineer PHC provision in SA, with strategic purchasing of services from both private and public sector providers by the NHI Fund, the sole purchaser of health services under NHI. ${ }^{[1]}$ It is noted that contracting in and contracting out of private health practitioners (alongside PHC provision by the established public sector PHC clinics) will be essential to strengthening and ensuring integrated services at the PHC level, in order to improve access to healthcare for the population while reducing the burden of disease. ${ }^{[1]}$

Currently, access to the private sector is primarily restricted to high-income earners in SA through private medical insurance schemes. However, while only $16.2 \%$ of the SA population is covered by costly private medical insurance schemes and predominantly utilises private providers, ${ }^{[1]}$ an important proportion of the lowincome segment of the SA population is choosing to access private PHC providers for a fee instead of accessing free care at a public sector clinic. It is estimated that $28 \%$ of SA households' normal place of consultation is the private sector ${ }^{[3]}$ In particular, it was estimated in 2006 that among those who were uninsured and with a household income <ZAR6 000 a month, $22.4 \%$ of their most recent outpatient visits were to private general practitioners (GPs) ${ }^{[4]}$ This is presumably due to greater perceived or experienced quality of care received at private PHC providers, reducing the need for additional visits, as well as shorter waiting times, which together decrease cost to patients in accessing PHC.

In recent years, a number of private providers in SA have established innovative models of PHC delivery that aim to expand access beyond insured medical scheme members and provide access to good-quality PHC services to under-served populations. These models move beyond the predominantly single-practice GP model 
that has traditionally served the private market and include nurserun and owned private practices, non-governmental organisation (NGO)-run PHC service centres with partial government support, and private doctors recruited by the National Department of Health $(\mathrm{NDoH})$ or donors to offer specific services (e.g. HIV testing and treatment), among others. These models have varying degrees of external support: some rely on access to in-kind contributions, some are reliant on donor or government funding, while others are entirely self-sufficient business entities relying on revenue and investor capital.

These private models of service delivery, if certified and accredited, may provide contracted-out PHC services to the populations they serve under NHI. Under NHI, the Contracting Unit for Primary Healthcare (located at the district level) will contract with certified and accredited public and private healthcare providers. ${ }^{[1]}$ In order to be accredited and reimbursed by the NHI Fund, the service provider must be certified by the Office of Health Standards Compliance, and, where relevant, provide proof of registration by the Health Professions Council of South Africa, the Nursing Council of South Africa, the South African Dental Council or the South African Pharmacy Council. The service provider must also be able to provide the minimum required range of personal healthcare services specified by the Minister of Health; allocate the appropriate number and mix of healthcare professionals to deliver the healthcare services specified by the Minister; adhere to treatment protocols and guidelines (including medicine prescribing); adhere to referral networks; submit information to the National Health Information Repository and Data System; and adhere to the national pricing regimen for services delivered. ${ }^{[5]}$

\section{Objectives}

The objective of this study was to describe the current private PHC delivery landscape outside the traditional GP model of private PHC. In particular, the objective was to identify and describe organisations targeting low-income, uninsured earners, a market that has not traditionally been the focus of private providers, and explore the role these organisations might play during the transition to NHI through thematic analysis of key informant interviews. The study forms part of a larger analysis to assess the cost and outcomes of these models of private PHC providers operating in this market relative to PHC service delivery at public sector clinics in SA for a defined subset of PHC services (HIV, tuberculosis (TB), diabetes and hypertension), with this study informing the selection of models to be included in the larger analysis.

\section{Methods}

The core selection criteria for inclusion in the PHC model evaluation were that the organisation:

- is a PHC service provider rather than a healthcare funder or managed care organisation outside of PHC

- offers PHC services, including treatment services, for at least one of the conditions/diseases identified for the broader study, namely HIV, TB, diabetes or hypertension

- primarily services the low-income, uninsured population, and has sites located appropriately for this population

- aims to grow the model beyond a single clinic.

Organisations were initially selected using purposeful sampling. This involved desktop research compiled in June and July 2017 using websites, news sites, published literature and grey literature, with search terms such as 'primary healthcare', 'private,' 'South Africa', 'innovation', 'provider,' 'user fee', 'low income' and 'uninsured'. This desktop research was also augmented with organisations known to the authors or collaborators. Additional providers were selected for interview through snowball sampling following recommendations from the initial sample of key informants until no further new providers were identified or responded. Sampling was closed at the end of August 2018

Key informant interviews were conducted between March and August 2018 with representatives of those private PHC provider organisations that met the above selection criteria. The key informants were founders, chief executive officers or senior managers who were involved with the strategic management of the organisation. Prior to the scheduled interview, identified key informants were approached via email, provided with information about the study and asked whether they would like to participate. Written informed consent was obtained from each interviewee who agreed to participate, including permission to audio-record the interview.

A semistructured interview guide with interviewer prompts was used for face-to-face interviews, and summaries of responses were captured on paper interview notes. The interview lasted between 60 and 120 minutes, and between two and four of the authors were present at each interview to ensure that information was consistently captured. During the interview, key informants were asked to describe their organisation with particular reference to the PHC services it offers, the population it serves (demographics, location, employment, insurance status, etc.) and the financing model, together with a general description of the model (site infrastructure, information and other systems, number and levels of staff, and patient numbers). We also asked respondents to describe factors that had facilitated or complicated the organisation's work so far.

Written responses from all the interviewers were captured in Excel 2016 (Microsoft, USA) and coded manually. Content analysis was guided by the interview framework, and coding themes were identified a priori based on the thematic areas included in the interview guide: financing model, staff, scope of services, size and visit volumes, target population, ease of access, and patient management systems. Additional sub-themes were included as they emerged and, where necessary, the audio recording was used to corroborate information.

Following this exercise, a workshop was held with all authors to ensure the consistency of the coded data and further in-depth analysis was conducted to define the focus of the analysis and determine key themes. In order to frame the key themes within the quality criteria planned to be used during the transition to NHI, these key themes were in part informed by the NHI accreditation criteria listed in the introduction above, while others were derived from the data. However, accreditation and contracting under NHI was not a major focus of this analysis. Table 1 summarises how these accreditation criteria match to one or more of our themes.

During the workshop, we also used information from the interviews to rank each organisation under each key theme. This was done by determining which organisations had the least of that particular characteristic and then ranking the organisations in order towards the one that had the most. For example, under the theme 'Degree of independence of grant, donor and/or government funding, organisations that were entirely reliant on user fees and commercial or private funding were ranked the most independent, whereas a public sector clinic was ranked the least independent as it was entirely reliant on government funds. For organisations that had a mix of funding, the funding-split proportions provided during the interviews were used to rank them accordingly. A typical public 


\begin{tabular}{|c|c|}
\hline NHI Fund Bill stipulation & Matching theme \\
\hline Minimum service package & $\begin{array}{l}\text { - Scope of services (TB, HIV, diabetes and hypertension only) } \\
\text { - Full scope of PHC services }\end{array}$ \\
\hline Appropriate number and mix of staff & - Highest healthcare worker cadre available on average visit \\
\hline $\begin{array}{l}\text { Statement of performance expectation in respect of } \\
\text { patient management, volume and quality of services } \\
\text { delivered, and access to services }\end{array}$ & $\begin{array}{l}\text { - Quality of care } \\
\text { - Patient visits/clinical staff per month } \\
\text { - Flexibility of access: opening hours, waiting time, location }\end{array}$ \\
\hline Submission of information to NHIRDS & $\begin{array}{l}\text { - Sophistication of patient management system } \\
\text { Interoperability with NHIRDS not included, as no specifications available yet. }\end{array}$ \\
\hline Adherence to national pricing regimen & $\begin{array}{l}\text { - User fee amount } \\
\text { Adherence to future NHI prices not included, as these have not been determined yet. }\end{array}$ \\
\hline Adherence to treatment protocols and guidelines & $\begin{array}{l}\text { Not included } \\
\text { All models mentioned that they abide by current treatment protocols and guidelines. } \\
\text { We will test this adherence in future patient-level research. }\end{array}$ \\
\hline Adherence to referral networks & $\begin{array}{l}\text { Not included } \\
\text { We did elicit referral pathways for the main services included in the study. Currently, } \\
\text { however, models' referral networks are constrained by patients' ability to pay for additional } \\
\text { private sector services. } \\
\text { Additional themes relating to funding model and scale of operations: } \\
\text { - Degree of independence of grant, donor and/or government funding } \\
\text { - Volume dependence of business model } \\
\text { - Government in-kind contributions } \\
\text { - Socioeconomic status of target population profile (insurance and employment status) } \\
\text { - Number of sites }\end{array}$ \\
\hline
\end{tabular}

$\mathrm{NHI}=$ National Health Insurance; $\mathrm{TB}=$ tuberculosis; PHC = primary healthcare; NHIRDS = National Health Information Repository and Data System. sector clinic was included as a point of reference in the ranking under each theme.

The study was approved by the Human Research Ethics Committee of the University of the Witwatersrand (ref. no. M171082) and the Institutional Review Board of the Boston University Medical Centre (ref. no. H-37230). The dataset generated and/or analysed during the study is not publicly available because it contains information that could compromise research participants' privacy/consent, but it is available from the corresponding author (SG) on reasonable request.

\section{Results}

\section{Overview of organisations and service models}

Of the 11 organisations identified, 8 agreed to participate and provide key informant interviews and 1 declined to participate. The other 2 organisations were contacted a minimum of five times (telephonically and by email) over a period of 6 months. At this point they were considered non-responsive and were excluded from the study.

The 8 different PHC service delivery models are summarised in Table 2. The organisations interviewed included one nurse-led franchise model, one clinical associate-led model, one community practice, one single-GP practice and one GP practice network, one contracted-out GP model, and two NGO-run clinic models, one in urban and semi-urban Gauteng Province and one in rural Limpopo Province. Common to all models was providing affordable access to private PHC services, primarily servicing the low-income, employed but uninsured population with facilities either conveniently located in under-served areas (e.g. informal settlements or rural farming areas) or with features facilitating easy access to under-served populations (by locating in commuter areas or close to places of work, or lowering the barriers to access with more flexible working hours and shorter waiting times). Funding models differed across the organisations, as did the extent of reliance on any one source of funding, be it government, private, donor or user fees. The package of PHC services across the models was determined by the scope of practice of the staff as well as the organisation's funding source and focus, but all models provided treatment for diabetes and hypertension, with HIV and TB treatment being largely restricted to those models $(n=4 / 8)$ that were able to access medicines at state sector contract prices through an agreement with government. None of the organisations was entirely reliant on donor funding; many relied on user fees and patient volumes in order to be or become sustainable $(n=4 / 8)$, and all but 2 had plans to expand their geographical footprint.

\section{Spectrum of service model characteristics}

Based on the respondents' replies and additional information shared by the organisations after the interviews, we summarised the service delivery models relative to one another along a spectrum regarding each key aspect (Fig. 1). A typical government PHC clinic is included as the reference case. 


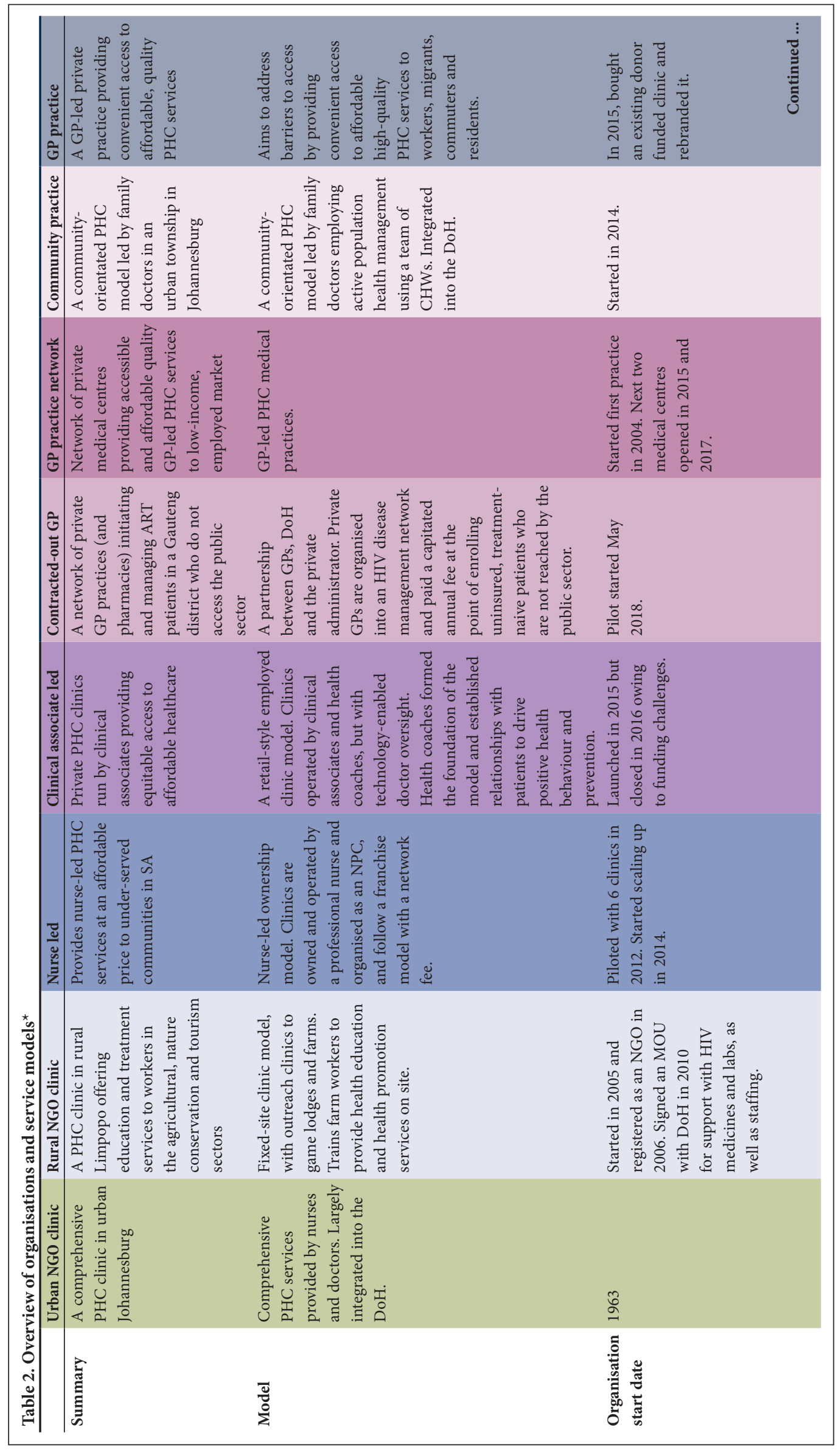




\begin{tabular}{|c|c|c|c|}
\hline & 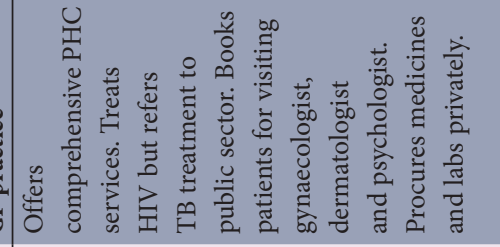 & 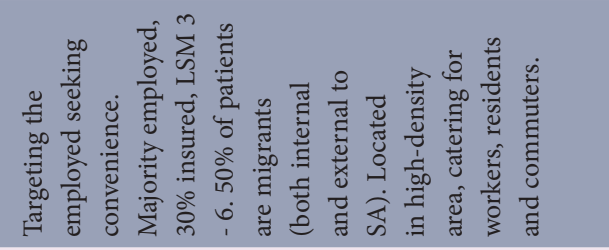 & 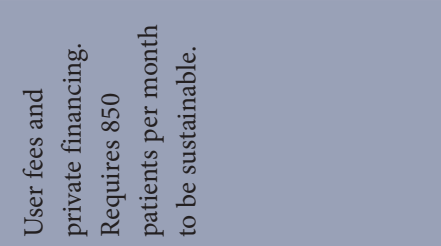 \\
\hline 菦 & 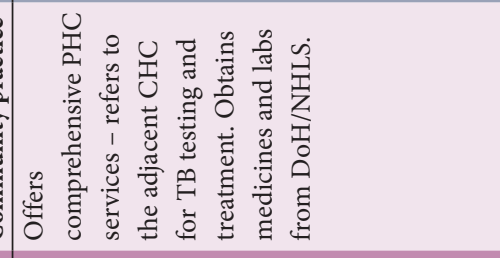 & 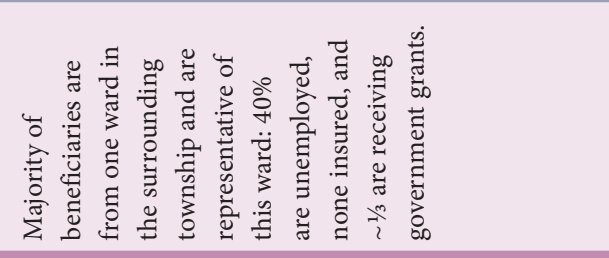 & 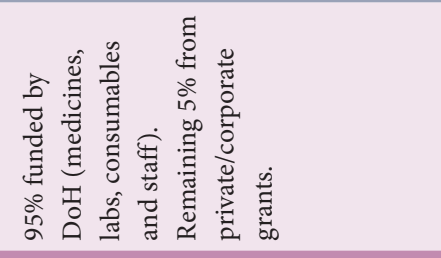 \\
\hline & 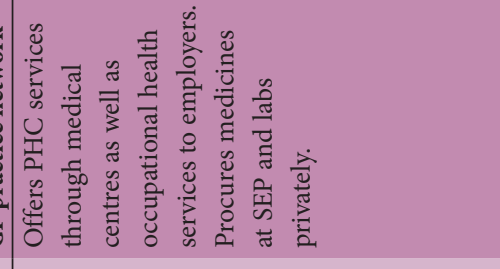 & 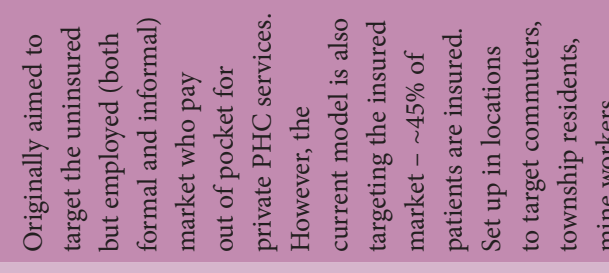 & 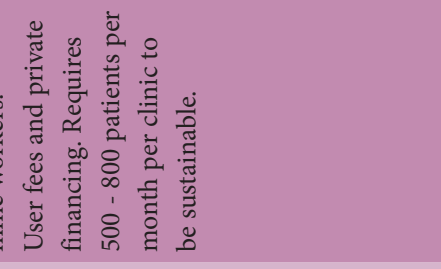 \\
\hline & 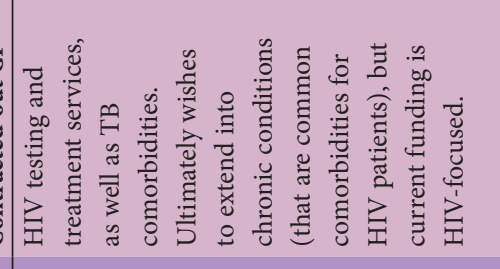 & 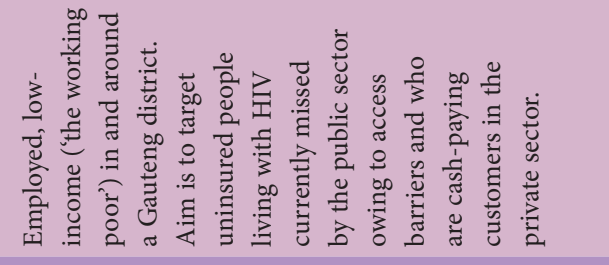 & 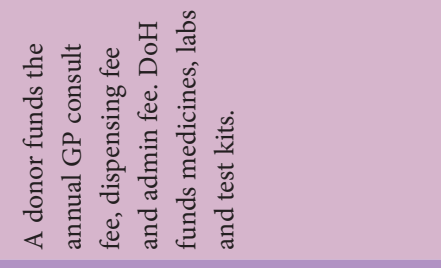 \\
\hline & 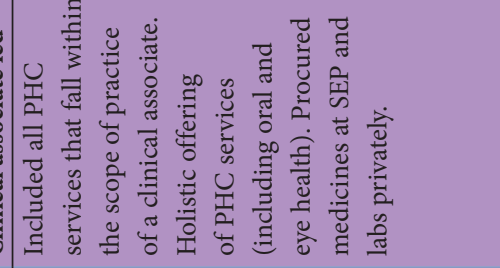 & 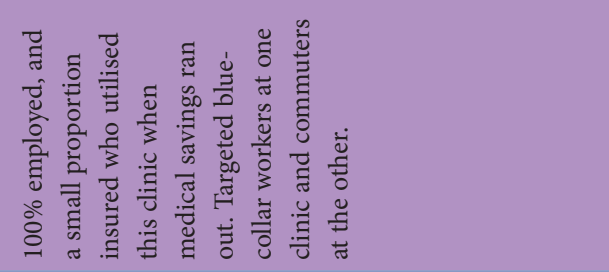 & 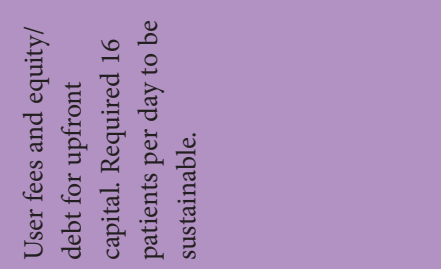 \\
\hline & 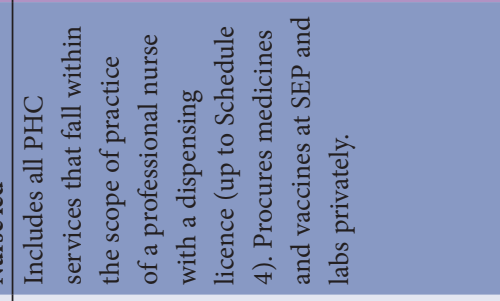 & 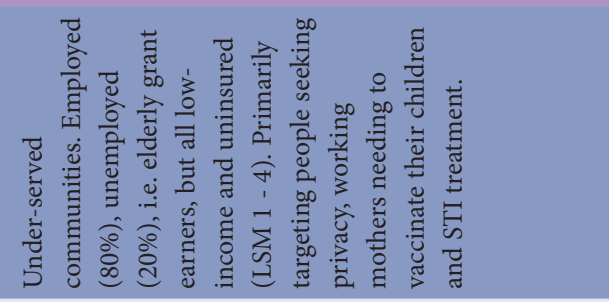 & 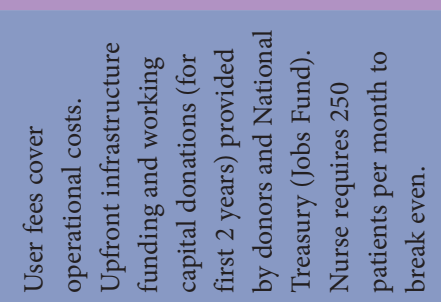 \\
\hline 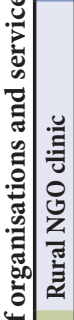 & 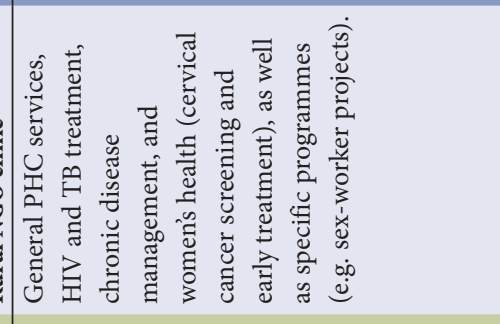 & 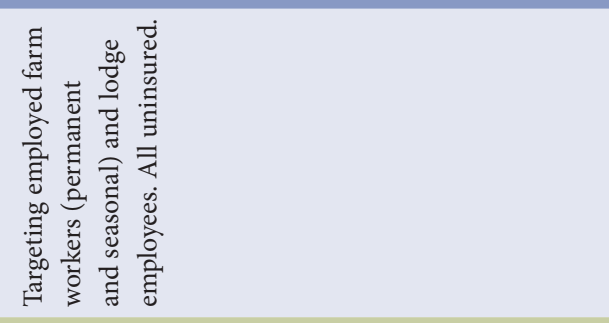 & 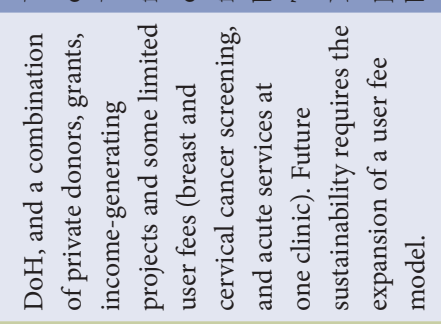 \\
\hline 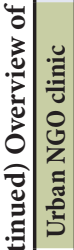 & 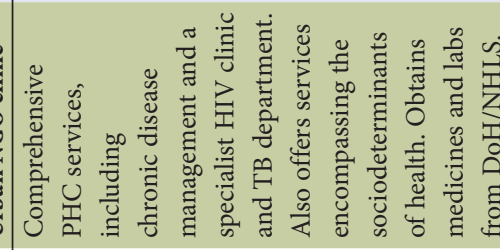 & 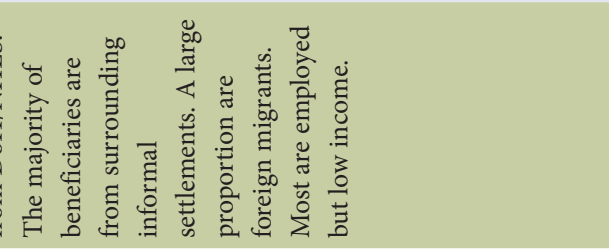 & 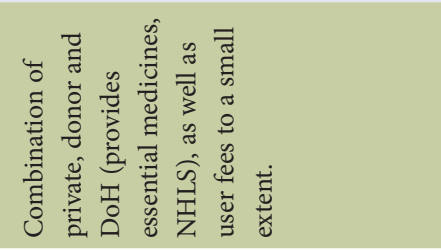 \\
\hline & 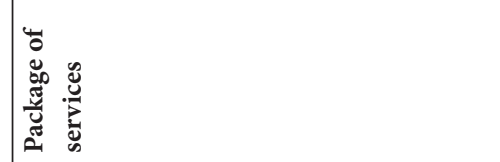 & 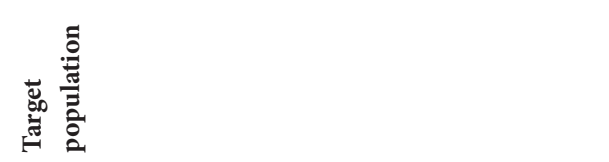 & 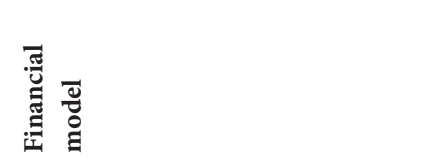 \\
\hline
\end{tabular}


From this summary, several trends emerge.

\section{What populations do the organisations target?}

All organisations required a robust strategy for balancing their goal of targeting populations with very low paying capacity and no or limited health insurance with the need to either cover costs or generate profit (in the case of for-profit organisations). While some models targeted the low-income uninsured who are also currently cash-paying customers in the private sector, the nurse-led model targeted those for whom a private GP was outside their affordability range, and both the rural and urban NGO models targeted the working poor who would not normally be cash-paying patients in the private sector. At least one model had to compromise on their initial intention of not serving the insured market, as they required additional demand among the insured to subsidise the non-insured market to ensure sustainability. However, this model did use GPs as their main healthcare providers, which is costlier. At least three models $(n=3 / 8)$ targeted crossborder migrants (non-SA nationals), as well as migrant labour (within SA) who struggle to access care during regular hours.

\section{What sources of funding do these organisations use?}

Most organisations had more than one source of funding, with different funds contributing in varying degrees to their overall budget. Half the organisations $(n=4 / 8)$ funded their capital or start-up costs privately or through commercial finance, while the other half used donor financing. Only 3 of 8 models were fully commercial models relying entirely on user fees to cover the operating costs, while a fourth was assisted with working capital donations for the first couple of years but thereafter was fully commercial. The other 4 organisations relied on a combination of donor and government support to cover operating costs, mostly in the form of access to public sector laboratory tests and medicines. The more dependent an organisation was on user fees and commercial/private funding for capital and startup costs as their primary form of funding, the more dependent they appeared to be on both patient volumes at any one site and the scale of operations, i.e. the number of sites, to be sustainable.

\section{What PHC services do the organisations offer and what factors influence the scope of services?}

To a large extent, the funding source dictated the range of services that organisations were able to offer. Since many organisations are volume-driven models, minor ailments, chronic disease management and testing and screening for HIV, TB and other diseases was an area many focused on, as patient volumes tend to be high, demand is more consistent than for other diseases, and the need for staff specialisation is limited.

However, this excluded the more specialised chronic infectious disease treatment for many: all the purely private models $(n=4 / 8)$ referred patients needing TB treatment to the public sector (including the government-funded community practice), and the provision of antiretroviral therapy was primarily limited to models that had access to public sector medicine stock $(n=4 / 8)$ owing to the prohibitive cost of HIV drugs in the private sector (ZAR496 per patient-month at the governmentregulated private sector single-exit price (SEP), compared with ZAR117 per month for the most used fixed-dose combination for first-line adult treatment). ${ }^{[6,7]}$ Three organisations without access to government stock did offer HIV treatment services, but their patients were required to purchase antiretroviral (ARV) medicines at SEP, thereby restricting access due to affordability; for example, the nurse-led model had just under $40 \mathrm{HIV}$ treatment patient visits on average per month, while their model served $\sim 16000$ patient visits a month. In contrast, two organisations estimated that the average cost of medicine per consultation was between ZAR30 and ZAR60 only, once HIV and TB treatment were excluded.

What strategies do organisations employ to increase technical efficiency and decrease costs in order to provide care that is affordable to their target population?

- Task shifting. All models used or had the option of using healthcare workers of a lower cadre when appropriate, e.g. replacing doctors with nurses or clinical 


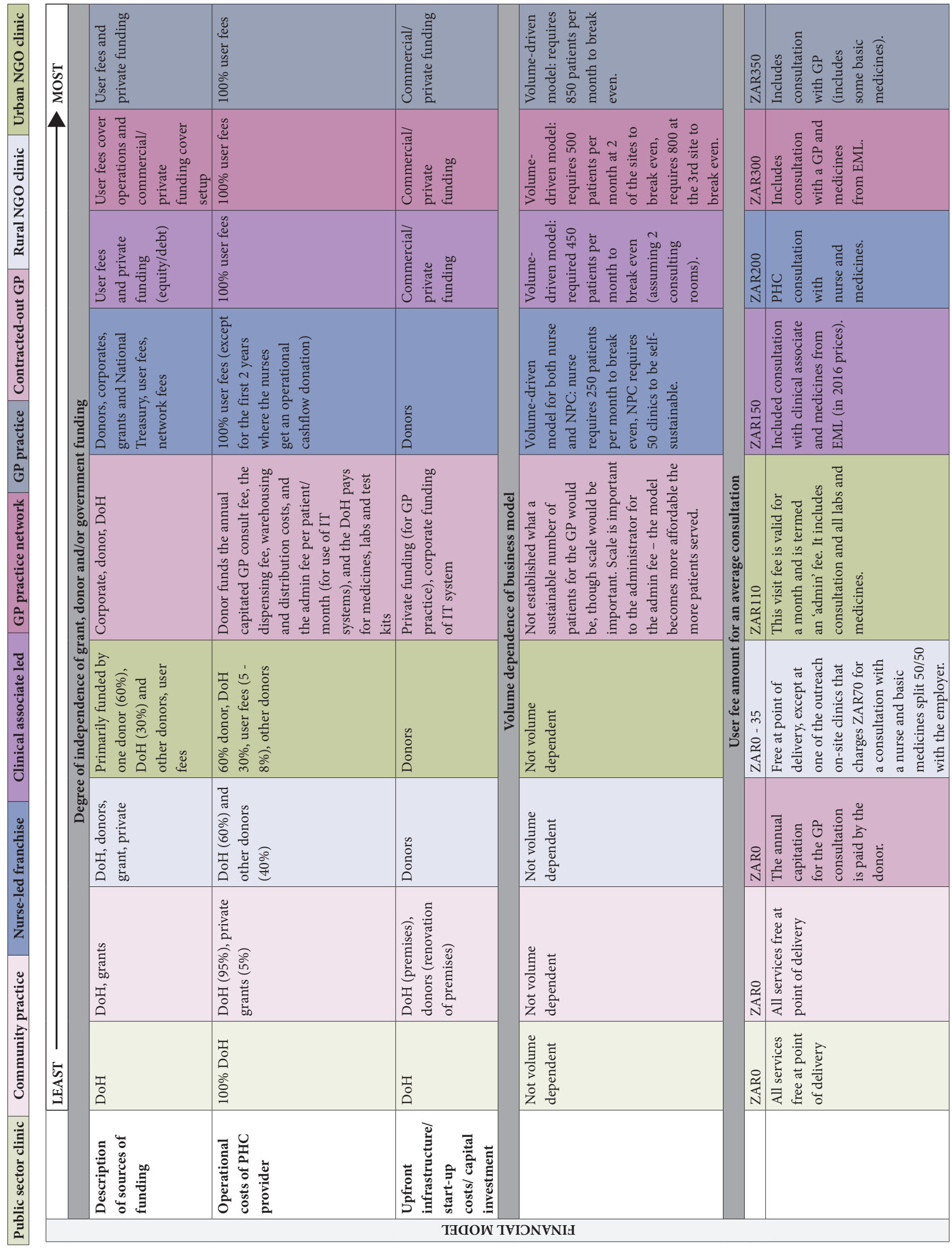




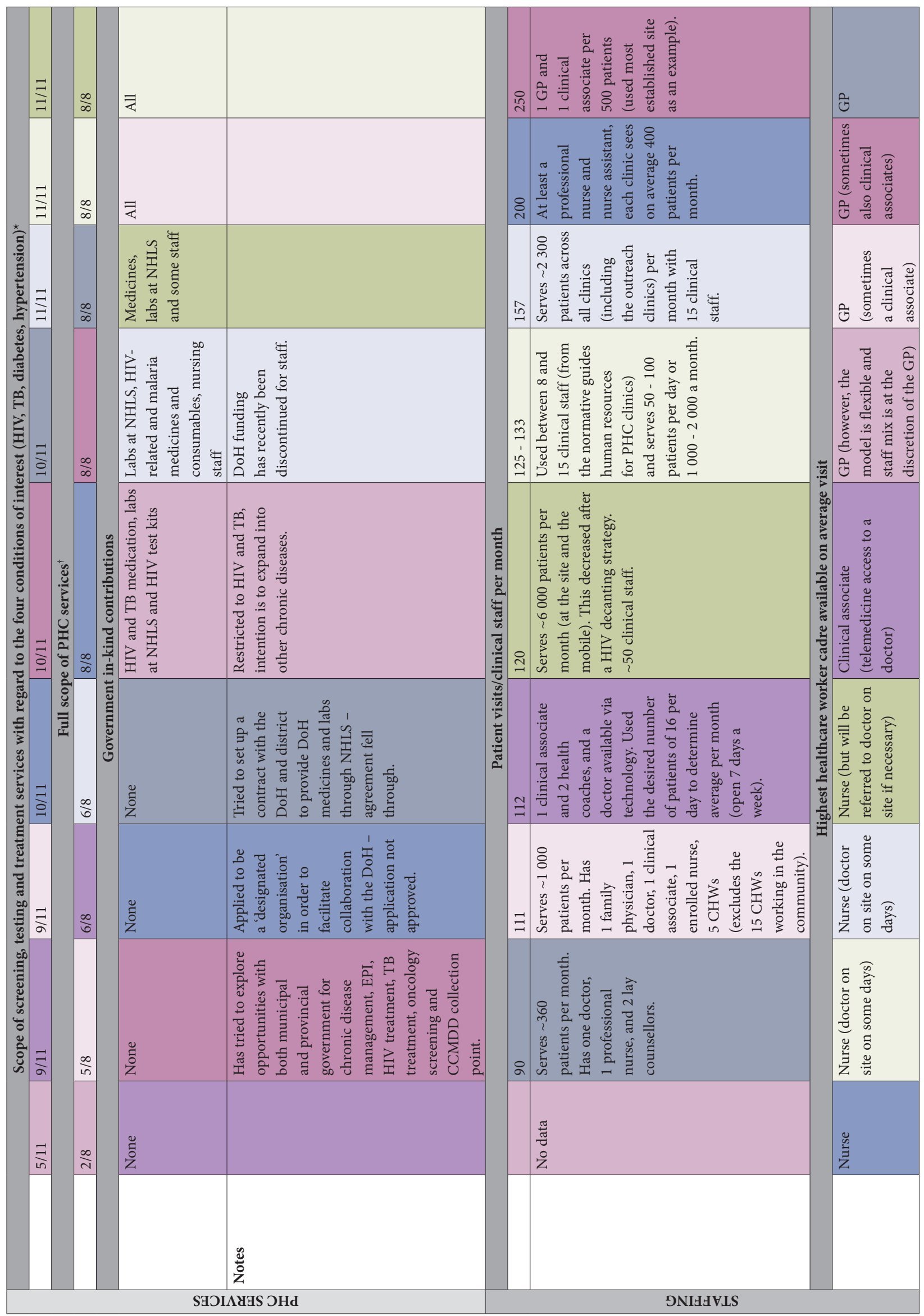




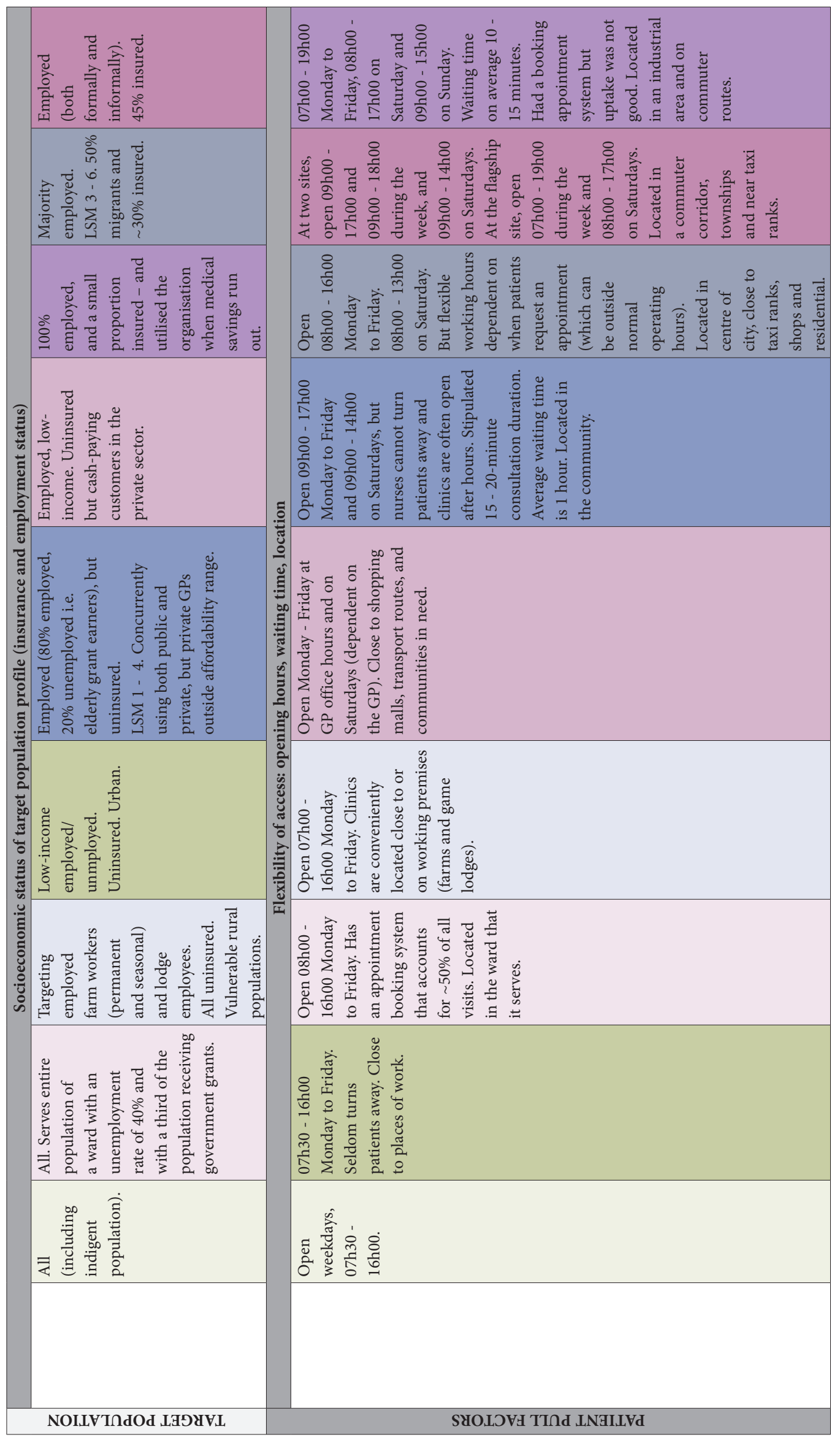




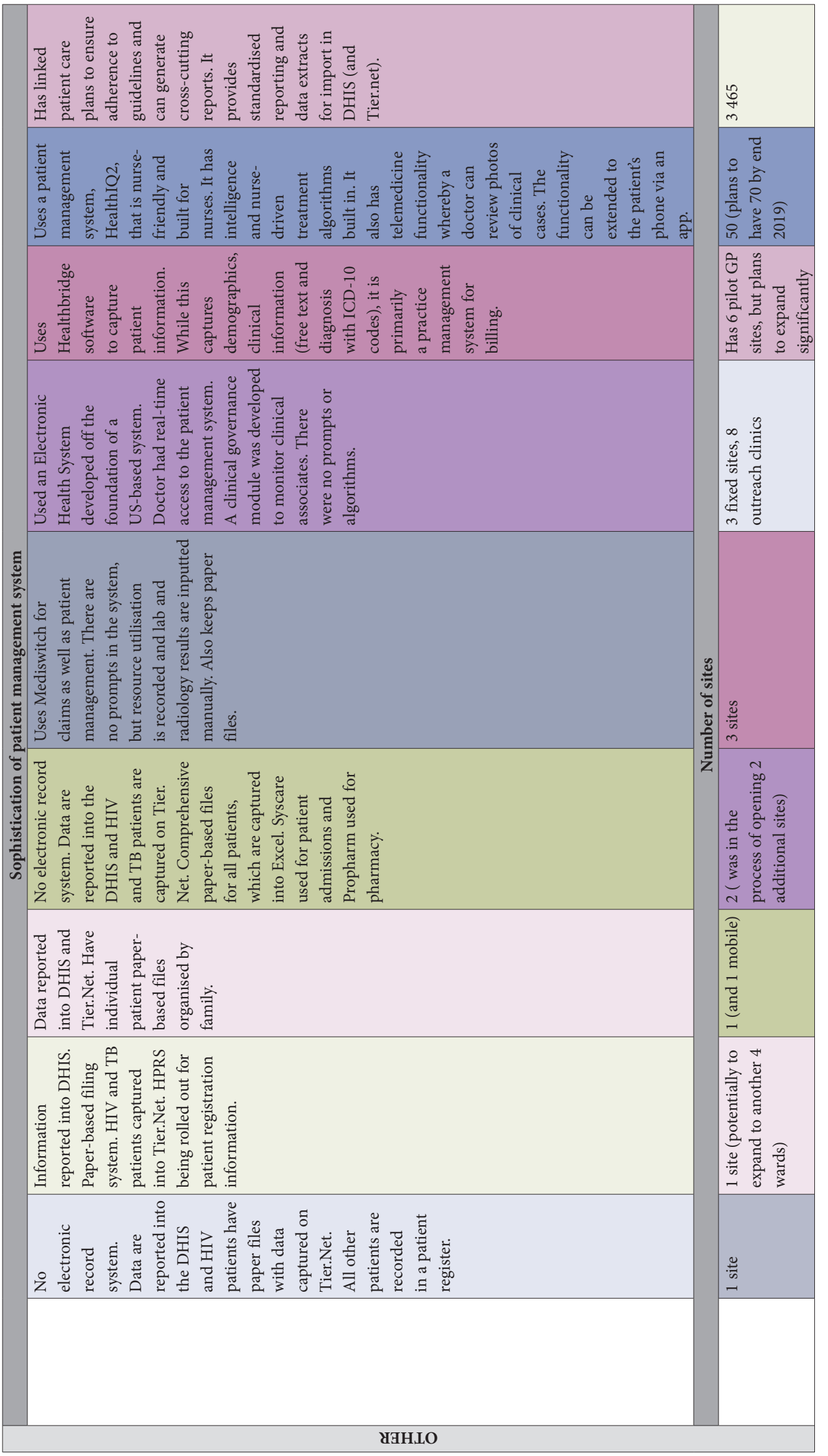

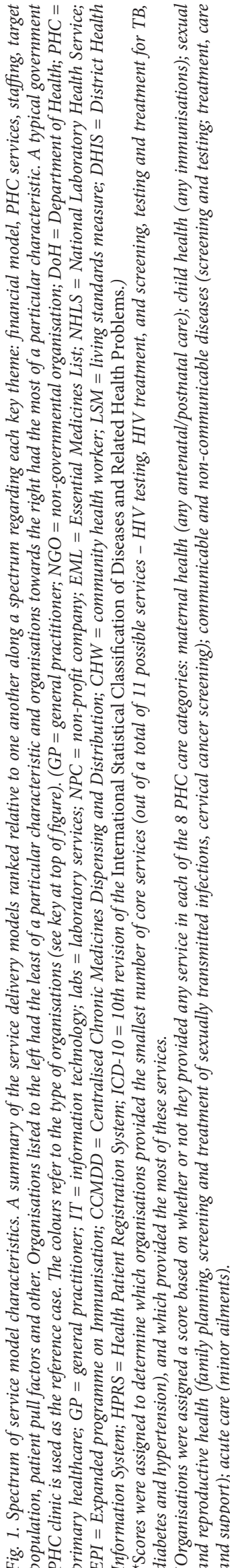


associates, and even in some cases using health promoters, community health workers or health coaches in place of nurses.

- Access to public sector medicine and laboratory tests. Some models $(n=4 / 8)$ have actively pursued and entered into partnerships with government to access medicines such as ARVs at government prices. In these same models, the National Health Laboratory Service (NHLS) provides laboratory testing services for some or all tests at no cost to the organisation.

- Scale/volume. Some models $(n=4 / 8)$ sought economies of scale by encouraging increased volumes per site in order to reduce the shared overhead cost of their operations per patient, as well as in specific cases increasing the number of sites in order to reduce the fixed above-facility cost (e.g. organisational management costs). One respondent from the GP practice model claimed that ' $\mathrm{PHC}$ is a game of numbers' and that the 'few who have made it have made it because of numbers and because of the location they are in'. One model used a loyalty card system (10th visit free) to encourage return visits, others were located in high-throughput commuter corridors $(n=7 / 8)$, while another used direct marketing $(n=1 / 8)$. All organisations expressed a willingness to contract with the NHI Fund, with NHI seen as a mechanism, inter alia, to reach scale.

- Use of technology. Most models used electronic patient management systems $(n=6 / 8)$, often augmented with an electronic health record $(n=5 / 8)$, to make record keeping more efficient and provide (sometimes real-time) guidance for lower-level staff through automated clinical algorithms providing prompts. Telemedicine was also employed in two models to provide real-time access to a remote medical doctor for medical oversight and guidance by lower-cadre healthcare staff.

\section{What strategies do organisations use to improve accountability} and quality of care?

- Ownership models. Some organisations used franchise or ownership models instead of salaried employment models. As a result, providers such as nurses who work to own their clinic and receive the profits are motivated to not only see as many patients as possible, but also to provide good quality of care in order to make sure customers return. Two organisations mentioned the importance of hiring staff with the right culture and vision.

- Electronic patient clinical management systems. Two $(n=2 / 8)$ organisations have invested in their own patient management system with prompts to the healthcare worker, or built-in care plans. For example, the contracted-out GP model used a patient care plan in order to standardise care across all GPs in the network.

- Flexibility of access. Flexibility of access for patients was enhanced in terms of location (close to home, work and situated in commuter areas), operating hours (including weekends) and short waiting times. A number of models used or explored appointment booking systems $(n=5 / 8)$, and at least two models mentioned the importance to their patients of privacy provided by a private clinic v. a public sector clinic (especially in terms of HIV treatment and treatment of sexually transmitted infections). These factors relating to ease and convenience of access are likely to increase patient satisfaction. One respondent commented that access is not just about the availability of services, it is also about convenience and the perception of quality.

- Comprehensive services. Some models offered auxiliary services such as dentistry and optometry in the same premises; others employed health promoters or health coaches in addition to the clinical staff. One model engaged in active population health management, deploying community health workers in the community to identify health issues. Additional services utilise common resources and the diversity of services available attracts more patients.

\section{Discussion}

We identified and described a number of private providers in SA who have established innovative models of PHC delivery that aim to provide access to good-quality PHC services at affordable rates. All models serve a population that seeks to access care outside the public sector despite not being privately insured, and is generally willing to pay for this care despite the same services being provided for free in the public sector.

We have explored these different models within the context of SA's transition to universal health coverage. As a system transitions towards universal health coverage, private providers could play a role in providing publicly funded services and encourage a publicprivate mix that ensures that the needs of the population are met. ${ }^{[8]}$ Contracting of private $\mathrm{PHC}$ providers or, more specifically, strategic purchasing of private PHC services are features of universal health systems in high- and middle-income countries. For example, primary care is largely delivered through contracted private GPs in the UK, ${ }^{[9]}$ and in Thailand, private PHC clinics are contracted to provide PHC services. ${ }^{[10-12]}$

NHI in SA is premised on the establishment of contracting units for PHC in each district, who identify the public and private facilities that the NHI Fund will contract with provided that they are accredited (according to the criteria listed at the beginning of this article) by the NHI Fund. This study did not seek to identify the organisations that government could contract with under NHI, or the specific form that this contracting might take. To do so, a more representative sample of GPs across all practice types (single-GP practices, group GP practices or multidisciplinary teams) would be necessary, as all of these will form the foundation of private PHC contracting under NHI. The under-representation of GPs and the small sample size, are limitations of this study, but the perspectives of GPs on NHI contracting, as well as different contracting options, are well documented elsewhere. ${ }^{[13-17]}$ However, what was clear was that while all other models (excluding the nurse-led model) either had a GP on site or could provide access to a GP on certain days or via telemedicine, task shifting to lower cadres of healthcare workers was an important cost-containment strategy. The current SA PHC model is based on nurse-run and led care through multidisciplinary teams in PHC clinics where access to a doctor is normally through referral. Nurse clinicians may be new for the private sector, but not for the public sector. Keeping the model flexible and the staff mix at the discretion of the GP or healthcare practitioner could allow for innovative practice types at lower cost and potentially higher quality.

The NHI Fund is also tasked with applying the principles of value-based purchasing by ensuring that the contracted service providers provide the services at 'the lowest possible price without compromising the quality of its services. ${ }^{[5]}$ Most of the low-cost private PHC service providers we reviewed have actively engaged strategies aiming to ensure the provision of affordable quality care. Within these strategies, scale is an important pivot towards achieving lower unit costs and spreading fixed costs across more paying patients, as well as access to government medicines and laboratory tests.

We found that the more reliant the organisation is on user fees and/or commercial and other private funding for capital and start-up costs, the more important scale and volume are to their model. This 
is because organisations are limited in their ability to raise the prices of their services owing to the low paying capacity of their patients, whose demand is likely to be quite elastic given the competitive constraint posed by free public sector services and generally low incomes. Instead, these organisations need to attract sufficient volumes. There seems to be an impression on the part of many organisations that a national or larger footprint, or establishing a network of providers, will facilitate contracting with the NHI Fund perhaps because higher patient volumes, up to a point, are required to ensure that the NHI capitation rate will make commercial sense (not dissimilar to the low price points of current user fees), and a larger network would reduce overall contractual or above-facility costs.

Furthermore, given that margins are tight and lowering prices to attract additional patient volumes is often not a sustainable option, these organisations rather need to compete on aspects of quality in order to attract sufficient volumes. This manifests itself in a greater focus on increasing patient satisfaction with the quality of the service, as well as other structural features (strategic site selection, friendly and welcoming staff, clean and inviting facilities, etc.) and also branding and marketing. We have, however, not attempted to determine whether there is a quality differential between the models or relative to the public sector model. We have also not tried to evaluate the difference in a salaried or ownership model's impact on staff incentives and motivation, and the subsequent quality of care delivered.

Another key observation from the exploratory analysis was that all the organisations interact to differing degrees with the $\mathrm{NDoH}$, and this affects the patient volumes they can afford to serve as well as what services they can offer. For example, we found that only organisations that receive medicines from government stock are able to offer the relatively more costly and specialised HIV and TB treatment services to any significant extent. Organisations are primarily responding to the needs of their clientele as well as financial constraints. Access to medicines at state prices could feasibly allow some of the organisations to expand their service offering. In future, should they be required to offer a more comprehensive service under NHI, it seems likely that these organisations would be able to meet these requirements without considerable difficulty (for example, if necessary, by contracting out the additional services). Furthermore, a number of organisations mentioned approaching the public sector with proposals regarding, for example, vaccination service delivery at government stock prices in order to enhance the government vaccination programme, or facilitating access to cancer screening for public sector patients at reduced rates. Little traction had been gained, according to these organisations, possibly owing to the challenges that both the public decision-makers and these private organisations face in operating in a regulatory grey area at the point at which the public and private sectors intersect, in particular during the transition period to NHI. The exception to this was the contracted-out GP model that had successfully negotiated a servicelevel agreement with a provincial department of health for HIV and TB testing and treatment services, but was hoping to expand its package of services once proof of concept and trust had been established.

Government, in particular the $\mathrm{NDoH}$, could enable innovation and encourage the development of more of these models by defining a regulatory framework and setting out the required processes for mutually beneficial interaction between the two sectors, as mentioned by the former Minister of Health in his Budget speech: 'Making sure that some of our programmes are undertaken by the private sector will contribute heavily in lessening our burden. For instance, we shall decant 50000 patients to 250 private GPs for ARV treatment between October 2018 and December 2020, and build up from there. The State will supply the ARVs and pay for the laboratories. The GPs will be paid their service fees. ${ }^{\text {'[18] }}$ However, without a clear policy framework for collaboration in the transition phase to NHI, it is difficult for the private sector to interact effectively with the government and provide services to their target population (insured, employed low income). The recent Health Market Inquiry recommended that 'strategic purchasing of available private capacity to supplement capacity in the public sector need not wait for the NHI. Government could, and should, already contract with the private sector where it needs capacity. ${ }^{\text {[19] }}$

\section{Conclusions}

We have provided an exploratory analysis of private PHC service delivery models serving the low-income, uninsured patient population, establishing factors that increase the efficiency of such service delivery and delineating combinations of strategies that could make these models successful both during the transition to $\mathrm{NHI}$ and during full-scale NHI implementation. A clear regulatory framework would act as a catalyst for further innovation and facilitate contracting. These existing models can enhance and complement government provision and could be scaled up to meet the needs of expanding PHC under NHI. Whether these models might be able to effectively provide care to their target population at a cost that is less than the public sector and with better outcomes, is the focus of further research. Understanding these models and the space and the parameters in which they operate is important.

Declaration. None.

Acknowledgements. We are grateful to the key informants for this study who generously gave of their time to share their insights with us.

Author contributions. SG and GM-R contributed equally to this work. SG, GM-R, JM and LL conceived the study. SG, GM-R, JM and KG conducted key informant interviews. SG and KG captured the interviews in Excel. SG, KG, GM-R, JM and LL analysed the data. SG and GM-R wrote the first draft of the manuscript. SG, GM-R, KG, JM and LL contributed to the writing of the manuscript. SG, KG, JM, LL and GM-R read and approved the final manuscript.

Funding. This study was made possible by the generous support of the American people through the President's Emergency Plan for AIDS Relief (PEPFAR) through the United States Agency for International Development (USAID) under the terms of Cooperative Agreements AID 674-A-12-00029 and 72067419CA00004 to $\mathrm{HE}^{2} \mathrm{RO}$. The contents are the responsibility of the authors and do not necessarily reflect the views of PEPFAR, USAID or the US government.

Conflicts of interest. JM has received funding from Discovery Fund to conduct research at one of the clinic sites used in this study.

\footnotetext{
1. National Department of Health, South Africa. National Health Insurance for South Africa - White Paper. 2017. http://www.health.gov.za/index.php/2014-03-17-09-09-38/strategic-documents/category/ 383-national-health-insurance (accessed 17 July 2018).

2. Kruk ME, Gage AD, Joseph NT, et al. Mortality due to low-quality health systems in the universal health coverage era: A systematic analysis of amenable deaths in 137 countries. Lancet 2018;392(10160):22032212. https://doi.org/10.1016/S0140-6736(18)31668-4

Statistics South Africa. General Household Survey 2016. Statistical Release P0318. 2017. https://www statssa.gov.za/publications/P0318/P03182016.pdf (accessed 29 October 2018).

Broomberg J. Consultative Investigation into Low Income Medical Schemes - Final Report. 2006 (1)

. Gatorate Dill, 2018. Governm Gazte No. 41725.635, 21 Jue 2018. h/ps/mm. nsurance-bill-2018-for-broader-public-comment_20180621-GGN-41725-00635 (accessed 2 September 2018)
} 
6. South African Medicine Price Registry. Database of Single Exit Price Medicine Prices. 2018. http://

7. National Department of Health, South Africa. Master Procurement Catalogue. 2018. http://www
. health.gov.za/index.php/component/phocadownload/category/196 (accessed 2 September 2018).

8. McPake B, Hanson K. Managing the public-private mix to achieve universal health coverage. Lancet 2016;388(10044):622-630. https://doi.org/10.1016/S0140-6736(16)00344-5

9. The Commonwealth Fund. International Profiles of Health Care Systems. 2017. https://www. commonwealthfund.org/sites/default/files/documents/___media_files_publications_fund report_2017_may_mossialos_intl_profiles_v5.pdf (accessed 2 September 2018).

10. Patcharanarumol W, Panichkriangkrai W, Sommanuttaweechai A, et al. Strategic purchasing and health system efficiency: A comparison of two financing schemes in Thailand. PLoS One 2018;13(4):113. https://doi.org/10.1371/journal.pone.0195179

11. Blecher M, Pillay A, Tangcharoensathien V, et al. Health financing lessons from Thailand for South Africa on the path towards universal health coverage. S Afr Med J 2016;106(6):4-5. https://doi. org/10.7196/SAMJ.2016.v106i6.10953

12. Tangcharoensathien V, Limwattananon S, Patcharanarumol W, et al. Achieving universal health coverage goals in Thailand: The vital role of strategic purchasing. Health Policy Plan 2015;30(9):11521161. https://doi.org/10.1093/heapol/czu120

13. Moosa S, Luiz J, Carmichael T, et al. Insights of private general practitioners in group practice on the introduction of National Health Insurance in South Africa. Afr J Prim Health Care Fam Med 2016;8(1):e1-6. https://doi.org/10.4102/phcfm.v8i1.1025
14. Moosa S. A path to full-service contracting with general practitioners under National Health Insurance. S Afr Med J 2014;104(3):155-156. https://doi.org/10.7196/SAMJ.7719

15. Surender R, van Nicke R, Alfes L. Is So h Afrea d The perspectives of general practitioners in one pilot site. S Afr Med J 2016;106(11):1092-1095. https://
doi.org/10.7196/SAMJ 2016 v106i11.10683 doi.org/10.7196/SAM).2016.v10611.10683

6. Hongoro $\mathrm{C}$, Funani $\mathrm{IN}$, Chitha $\mathrm{W}$, et al. An assessment of private general practitioners contracting for public health services delivery in O.R. Tambo District, South Africa. J Public Health Afric 2015;6(2):525. https://doi.org/10.4081/jphia.2015.525

17. Mureithi L, Burnett JM, Bertscher A, English R. Emergence of three general practitioner contractingin models in South Africa: A qualitative multi-case study. Int J Equity Health 2018;17(1):107. https:// doi.org/10.1186/s12939-018-0830-0

18. South African Government. Minister Aaron Motsoaledi: Health Dept Budget Vote 2018/19. 15 May 2018. https://www.gov.za/speeches/minister-aaron-motsoaledi-health-dept-budget-vote-201819-15may-2018-0000 (accessed 2 September 2018).

19. Competition Commission of South Africa. Health Market Inquiry: Provisional Findings and Recommendations Report. 5 July 2018. http.//www.compcom.co.za/wp-content/uploads/2018/07/ Health-Market-Inquiry-1.pdf (accessed 2 September 2018).

Accepted 4 April 2019 